УДК 81’322.4’25-051:378.147.091.33

DOI:

Алла Ольховська, доктор педагогічних наук, професор кафедри перекладознавства імені Миколи Лукаша Харківського національного університету імені В. Н. Каразіна Анастасія Хоменко, студентка другого курсу магістратури кафедри перекладознавства імені Миколи Лукаша

Харківського національного університету імені В. Н. Каразіна

\title{
ВПЛИВ ВИКОРИСТАННЯ НЕЙРОННОЇ СИСТЕМИ МАШИННОГО ПЕРЕКЛАДУ НА ЯКІСТЬ ПЕРЕКЛАДУ ТЕКСТІВ У ГАЛУЗІ ЕКОНОМІКИ
}

У статті описано експериментальне дослідження із вивчення впливу трьох нейронних систем машинного перекладу (Google Translate, Microsoft Translator, online-translator.eu) на якість перекладу уривку тексту економічної тематики в аспекті кількості помилок різних типів. Одержані результати підтвердили сформульовану нами гіпотезу: різні нейронні системи машинного перекладу надають переклад одного і того самого тексту економічної тематики різної якості, яку можна відстежити, порахувавши кількість помилок у кожному виконаному перекладі. Відрив у результатах, продемонстрованих обраними нами системами не можна назвати великим, проте найкращу якість перекладу тексту економічної тематики зафіксовано у Google Translate.

Ключові слова: машинний переклад; нейронні системи машинного перекладу; економічна тематика; інформаційно-комунікаційні технології у перекладі; підготовка перекладачів.

Рис. 1. Табл. 1. Літ. 11.

Alla Olkhovska, Doctor of Sciences (Pedagogy), Professor of the Mykola Lukash Translation Studies Department of V. N. Karazin Kharkiv National University Anastasiya Khomenko, Second-year Graduate Student of the Mykola Lukash Translation Studies Department of V. N. Karazin Kharkiv National University

\section{THE IMPACT OF USING A NEURAL MACHINE TRANSLATION ENGINE ON THE QUALITY OF TRANSLATION OF TEXTS IN THE FIELD OF ECONOMY}

The article describes an experimental research the aim of which was to study the impact of using three neural machine translation engines (Google Translate, Microsoft Translator, online-translator.eu) on translation quality of an economic text in terms of the number of errors of different types. In order to achieve the aim we solved a number of tasks: formulated a research hypothesis, selected an economic text and three neural machine translation engines, determined the optimal procedure for evaluating the results of translations performed by the selected neural machine translation engines, translated the text by means of the selected neural machine translation engines, assessed the translations according to the established evaluation procedure, analyzed and interpreted the results obtained during the empirical research. The evaluation procedure used in our study was developed by Leonid Chernovaty who suggested establishing penal points for certain types of errors. Thus, he distinguishes three types of errors: first type errors - serious errors that distort the content of the original text or simply omit certain semantic fragments (1,0 penal point is given); second type errors - errors that could theoretically affect the understanding of the content of the original text, that is when the information is transmitted ambiguously, and the translation provides for the possibility of broad interpretation, which may be erroneous (0,5 penal point is given); third type errors - minor errors that do not affect the content of the original text, but which can spoil the impression of the translated text: incorrect punctuation, incorrect spelling, grammatical errors, etc. (0,1 penal point is given). The subject of the research, its purpose and tasks led to the use of such empirical methods as a control translation of an economic text by means of three neural machine translation engines (Google Translate, Microsoft Translator, online-translatoreu), quantitative method of processing experimental data. The obtained results confirmed the hypothesis formulated in the beginning of the study: different neural machine translation engines provide translation of the same economic text of different quality, which can be traced by counting the number of errors in each performed translation. The gap in the results demonstrated by our engines is not crucial, but the translation of the best quality was performed by Google Translate.

Keywords: machine translation; neural machine translation engines; economic domain; information and communication technologies in translation; translator's training.

П остановка проблеми. Постійне зростання обсягів перекладу економічної літератури у світі призводить до необхідності використання перекладацьких інформаційно-комунікаційних технологій, без яких професійних перекладач вже не в змозі виконувати роботу швидко ті конкурувати на ринку перекладацьких послуг. 


\section{ВПЛИВ ВИКОРИСТАННЯ НЕЙРОННОӤ СИСТЕМИ МАШИННОГО ПЕРЕКЛАДУ НА ЯКІСТЬ ПЕРЕКЛАДУ ТЕКСТІВ У ГАЛУЗІ ЕКОНОМІКИ}

Останнім часом особливого розвитку зазнали системи машинного перекладу, які пропонують переклад належної якості, часто безкоштовно та дуже швидко - майже миттєво. Найвищу якість перекладу на сьогоднішньому етапі пропонують нейронні системи машинного перекладу, а тому їх можна було б використовувати з метою підвищення продуктивності виконання перекладів в галузі економіки.

Аналіз основних досліджень і публікацій. Економічний переклад все частіше стає об'єктом наукових досліджень, зокрема вивчалися: особливості перекладу економічних текстів [9], переклад новин про фінанси [10], ключові труднощі перекладу текстів економічної тематики та помилки, яких перекладачі припускаються найчастіше [7], когнітивний підхід до перекладу метафор у текстах економічного спрямування [8], типологія економічних текстів та вибір методу перекладу [1], особливості перекладу фінансовоекономічних текстів [6] та багато інших проблем.

Безперечно, усі перелічені праці зробили значний внесок у дослідження перекладу текстів економічної тематики, проте нам не вдалося знайти публікацій, які були б присвячені питанням вивчення економічних текстів 3 точки зору машинного перекладу: наскільки добре системи машинного перекладу різних типів можуть перекладати тексти економічної тематики, наскільки добре такі системи передають економічну термінологію мовою перекладу, скільки потрібно витратити часу на постредагування економічних текстів людиніперекладачеві та наскільки системи машинного перекладу різних типів (зокрема нейронні) здатні полегшити та прискорити перекладацький процес? Усі ці питання потребують ретельного вивчення, що й робить наше дослідження актуальним.

Мета дослідження - вивчити вплив використання нейронних систем машинного перекладу на якість перекладу текстів у галузі економіки в аспекті кількості помилок різних типів.

Реалізація сформульованої нами мети передбачає розв'язання низки завдань:

- сформулювати гіпотезу дослідження;

- відібрати уривка тексту економічної тематики для проведення дослідження;

- відібрати нейронні системи машинного перекладу;

- визначити оптимальну процедуру оцінки результатів перекладу обраними нейронними системами машинного перекладу;

- виконати переклад уривку тексту засобами обраних систем машинного перекладу;

- перевірити одержані переклади за встановленою процедурою оцінки;
- проаналізувати та інтерпретувати результати, одержані в ході емпіричного дослідження.

Матеріалом дослідження виступають три тексти перекладу уривка тексту економічного спрямування, виконані засобами нейронних систем машинного перекладу Google Translate, Microsoft Translator, online-translator.eu.

Предмет дослідження, його мета та завдання зумовили використання таких емпіричних методів: контрольний переклад уривка тексту економічного спрямування засобами трьох сучасних нейронних систем машинного перекладу (Google Translate, Microsoft Translator, onlinetranslator.eu), кількісний метод обробки одержаних експериментальних даних.

Виклад основного матеріалу. Експериментальне дослідження з вивчення впливу використання нейронної системи машинного перекладу на якість перекладу текстів у галузі економіки було проведене за такими загальновизнаними етапами, як: організація, реалізація, констатація та інтерпретація [3].

Перед початком дослідження нами було сформульовано гіпотезу: різні нейронні системи машинного перекладу будуть надавати переклад одного і того самого тексту економічної тематики різної якості, яку можна відстежити, порахувавши кількість помилок у кожному виконаному перекладі. Наша гіпотеза надає можливість передбачити такий наслідок: у результаті проведення дослідження ми зможемо встановити, яка з обраних нами нейронних систем машинного перекладу демонструє вищу якість при перекладі текстів економічного спрямування. Така інформація здатна значною мірою допомогти як майбутнім перекладачам, так і професійним практикуючим фахівцям скоріше та легше обрати собі в допомогу безкоштовну нейронну систему машинного перекладу.

Наступним кроком став відбір уривка тексту економічної тематики для проведення емпіричного дослідження. 3 цією метою ми вирішили звернутися до професійної економічної літератури. Нашу увагу привернула фундаментальна праця в галузі макроекономіки Грегорі Манків [11] та їі офіційний переклад [2]. Наявність офіційного професійного перекладу відігравала для нас особливо важливе значення, оскільки для перевірки перекладів нам потрібен був еталонний переклад. Варіантів його отримання було декілька. По-перше, ми могли його виконати самостійно, однак, оскільки нам бракує знань з економічної тематики, наш переклад міг виявитися не повністю еталонним. По-друге, професійний переклад можна було б замовити в 


\section{ВПЛИВ ВИКОРИСТАННЯ НЕЙРОННОӤ СИСТЕМИМАШИННОГОПЕРЕКЛАДУ НА ЯКІСТЬ ПЕРЕКЛАДУ ТЕКСТІВ У ГАЛУЗІ ЕКОНОМІКИ}

перекладацькій агенції, однак це коштувало б досить дорого, а бюджет нашого дослідження не передбачав таких витрат. Саме тому ми зупинилися на праці, яка вже має офіційний переклад та $є$ дуже вагомим доробком у галузі макроекономіки.

Для того, щоб отримані нами результати були показовими, ми вирішили обрати три системи машинного перекладу. Оскільки, бюджет нашого дослідження є доволі обмеженим, ми не могли скористатися платними системами машинного перекладу, а тому в полі нашої уваги опинилися лише системи типу open-source, тобто з відкритим кодом (безкоштовне використання).

Також, зважаючи на обмеженість місця на нашому персональному комп'ютері, нас не влаштовував варіант завантаження та встановлення нового програмного забезпечення, а тому було прийняте рішення скористатися онлайновими перекладачами, які відкриваються безпосередньо у браузері комп'ютера.

Керуючись згаданими критеріями, ми обрали такі нейронні системи машинного перекладу: Google Translate, Microsoft Translator, onlinetranslator.eu.

3 метою визначення оптимальної процедури оцінки результатів перекладу обраними нейронними системами машинного перекладу ми звернулися до праць відомого дослідника у галузі методики викладання перекладу професора Л. Черноватого [4; 5], який розробив систему оцінювання письмових перекладів за допомогою виставлення штрафних балів за певні типи помилок. Усього в межах моделі виокремлено три типи помилок, а саме:

- перший тип - серйозні помилки, які перекручують зміст тексту оригіналу або пропуск певних смислових фрагментів. За цей тип помилок передбачено виставлення одного штрафного балу;

- другий тип - помилки, які теоретично можуть вплинути на розуміння змісту тексту оригіналу, тобто коли інформацію передано неоднозначно, та передача передбачає можливість широкої інтерпретації, яка, у тому числі, може бути і помилковою;

- третій тип - незначні помилки, які не впливають на зміст тексту оригіналу, але через які може справлятися прикре враження стосовно тексту перекладу: неправильна пунктуація, неправильна орфографія, граматичні помилки тощо.

Система оцінювання, розроблена Л. Черноватим, оптимальна у тому плані, що є легкою та зручною у використанні, усі три типи помилок дуже легко визначаються та розрізнюються, а користування системою дає змогу перевірити переклади дуже швидко.

Наступним кроком нашого дослідження став аналіз отриманих результатів, для чого нам необхідно їх порівняти між собою. Найкращий спосіб зробити це - побудувати таблицю та діаграму, у яких було б наведено усі одержані результати, що уможливимо б легке зіставлення даних.

Таким чином, у таблиці 1 представлено результати в штрафних балах по текстах перекладу, виконаних засобами усіх трьох нейронних систем машинного перекладу, а саме: Google Translate, Microsoft Translator та onlinetranslator.eu

Як випливає з таблиці 1, досить великий розрив у межах першого типу помилок ми зафіксували між системами Google Translate i onlinetranslator.eu, причому різниця складає 4,0 штрафні бали, що є досить показовим результатом. Різниця між Google Translate i Microsoft Translator та Microsoft Translator i online-translator.eu $\epsilon$ не настільки великою та складає усього 2,0 штрафні бали. Найменше помилок першого типу припустився Google Translate, усього 7,0 штрафних балів.

У межах помилок другого типу різниця між системами є не такою суттєвою. Так, найбільше відрізняються результати у Google Translate i Microsoft Translator. Так, у Google Translate спостерігається на 2,0 штрафні бали більше, різниця між Microsoft Translator i onlinetranslator.eu є ще несуттєвішою - усього 0,5 штрафного бала, тобто online-translator.eu припустився на одну помилку другого типу більше.

У межах третього типу помилок найменшу кількість штрафних балів зафіксовано у нейронної системи машинного перекладу Google Translate - 32,6 штрафного бала, у той час як найбільша кількість помилок спостерігається в системи Microsoft Translator - 40,7 штрафного бала. Різниця між продемонстрованими результатами складає 8,1 штрафних балів, що є найбільшим розривом серед усіх трьох категорій. Дешо меншу різницю спостерігаємо між результатами Microsoft Translator i online-translator.eu, вона становить 3,6 штрафного бала, у той час як різниця між Google Translate i online-translator.eu складає 4,5 .

Найпоказовішими є узагальнені результати, продемонстровані нейронними системами машинного перекладу та наведені у самому кінці нашої таблиці.

Згідно з таблицею, найкращий результат 


\section{ВПЛИВ ВИКОРИСТАННЯ НЕЙРОННОЇ СИСТЕМИМАШИННОГОПЕРЕКЛАДУ НА ЯКІСТЬ ПЕРЕКЛАДУ ТЕКСТІВ У ГАЛУЗІ ЕКОНОМІКИ}

Таблиця 1.

Результати виконання перекладу тексту у галузі економіки засобами нейронних систем машинного перекладу Google Translate, Microsoft Translate тa online-translator.eu

\begin{tabular}{|c|c|c|c|}
\hline \multirow[t]{2}{*}{ Типи помилок } & \multicolumn{3}{|c|}{ Кількість штрафних балів } \\
\hline & Google Translate & Microsoft Translate & online-translator.eu \\
\hline $\begin{array}{c}\text { Помилки першого типу (1,0 } \\
\text { штрафний бал) }\end{array}$ & 7,0 & 9,0 & 11,0 \\
\hline $\begin{array}{c}\text { Помилки другого типу (0,5 } \\
\text { штрафного балу) }\end{array}$ & 12,5 & 10,5 & 11,0 \\
\hline $\begin{array}{c}\text { Помилки третього типу (0,1 } \\
\text { штрафного балу) }\end{array}$ & 32,6 & 40,7 & 37,1 \\
\hline Загальна кількість помилок & 52,1 & 60,2 & 59,1 \\
\hline
\end{tabular}

зафіксовано у нейронної системи машинного перекладу Google Translate: загальна кількість штрафних балів, набрана системою складає 52,1, найгірший результат - у системи Microsoft Translator: 60,2 штрафного бала. Проміжну позицію зайняла нейронна система onlinetranslator.eu, набравши 59,1 штрафного бала.

Однак слід відзначити той факт, що різниця між загальним результатом, продемонстрованим Microsoft Translator i online-translator.eu не $є$ надто суттєвою і становить усього 1,1 штрафного бала, у той час як різниця з системою Google Translate вже є суттєвішою.

Як показують наші результати, нейронна система машинного перекладу online-translator.eu на 7,0 штрафних балів гірше впоралася 3 перекладом тексту економічної тематики порівняно з системою Google Translate, a перекладач Microsoft Translator продемонстрував результат гірший від системи Google Translate на 8,1 штрафного бала.

Загальні результати нашого експериментального дослідження унаочнено на рис. 1 .

Як видно з рис. 1, результати перекладу тексту, які продемонстрували усі три нейронні системи машинного перекладу, не надто різняться між собою, причому це стосується усіх трьох типів помилок. Як бачимо, стовпчики за першим та другим типом помилок по всіх трьох системах не надто відрізняються за висотою та перебувають майже на однаковому рівні.

Дещо помітніші коливання можна спостерігати в межах третього типу помилок. Тут суттєво нижчим $є$ стовпчик Google Translate, у той час як різниця між висотою стовпчиків Microsoft Translator та online-translator.eu $€$ майже непомітна.

Стосовно останніх стовпчиків, які демонструють узагальнені результати по всіх

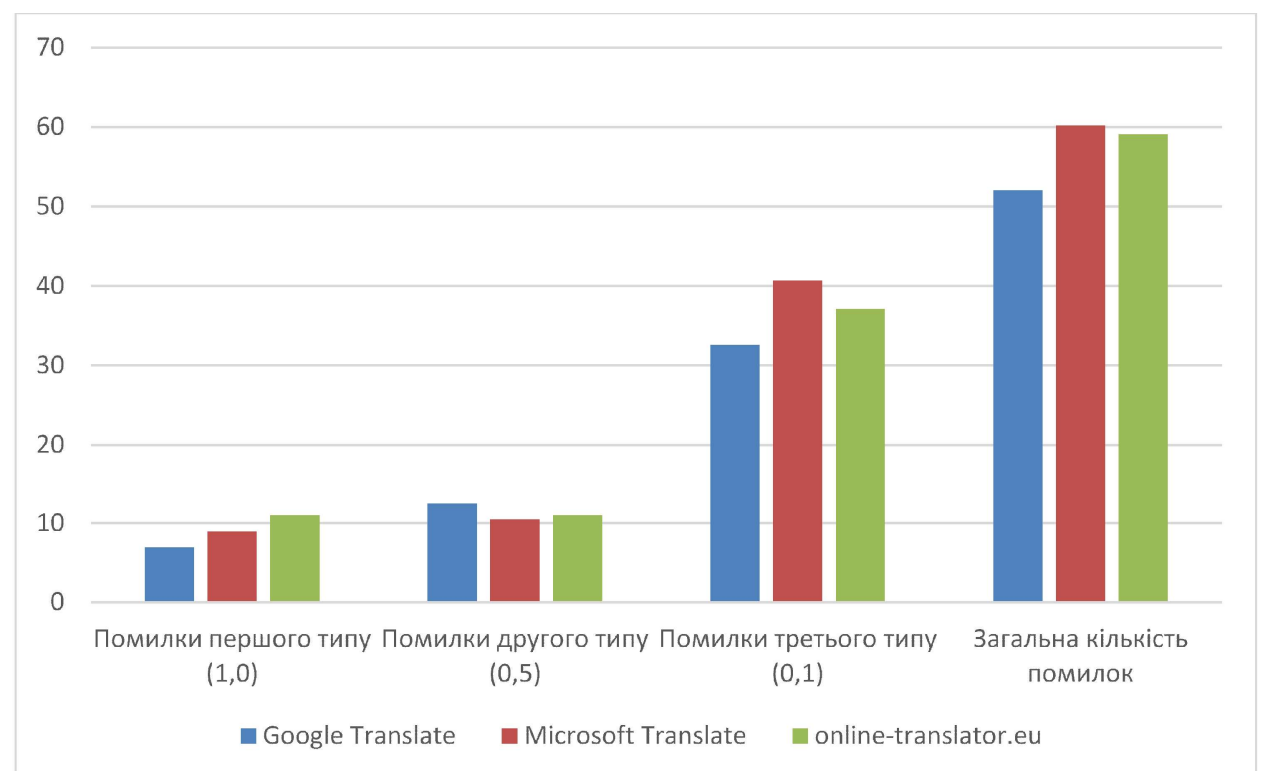

Рис. 1. Результати виконання перекладу тексту у галузі економіки засобами нейронних систем машинного перекладу Google Translate, Microsoft Translator i online-translator.eu 


\section{ВПЛИВ ВИКОРИСТАННЯ НЕЙРОННОЇ СИСТЕМИМАШИННОГОПЕРЕКЛАДУ НА ЯКІСТЬ ПЕРЕКЛАДУ ТЕКСТІВ У ГАЛУЗІ ЕКОНОМІКИ}

нейронних системах машинного перекладу, які ми використали в межах нашого дослідження, то бачимо, що загальний результат є дещо кращим у системи Google Translate, у той час як результат двох останніх систем (Microsoft Translator та online-translator.eu) $є$ практично однаковим і дещо гіршим.

Висновки та перспективи подальших досліджень. Таким чином, ми дійшли висновку, що гіпотеза, сформульована нами на початку проведення експериментального дослідження, підтвердилася: різні нейронні системи машинного перекладу дійсно продукують переклад одного і того самого тексту економічної тематики різної якості, яку ми відстежили, порахувавши кількість помилок в межах їх трьох типів у кожному виконаному перекладі.

За результатами нашого дослідження, відрив між нейронними системами машинного перекладу Google Translate, Microsoft Translator та onlinetranslator.eu не можна назвати великим, проте все таки найкраща якість перекладу тексту у галузі економіки спостерігається у Google Translate. Найімовірніше за все користувачі відчувають кращу якість системи, що може пояснити їі високу популярність та частоту використання, у тому числі і студентами.

Одержані результати у жодному разі не можна назвати остаточними, адже кількість нейронних систем машинного перекладу, обраних для проведення дослідження, є досить обмеженою, а тому доцільно було б провести аналогічне дослідження із використанням більшої кількості нейронних систем машинного перекладу.

Беручи до увагу широту економічної галузі, уривок тексту лише макроекономічної тематики також $є$ певним обмежувальним фактором, а тому доцільно провести подібні дослідження використовуючи більше текстів із різноманітних галузей економічної науки, а також більшу кількість нейронних систем машинного перекладу.

Також, перспективу вбачаємо у проведенні подібних досліджень із використанням систем машинного перекладу, які мають у своїй основі інші алгоритми роботи, а не лише нейронний, оскільки теоретично використання інших систем (наприклад, гібридного типу, тобто таких, які поєднують декілька алгоритмів роботи) може сприяти підвищенню якості машинного перекладу текстів економічної тематики.

\section{ЛІТЕРАТУРА}

1. Кобзар О. І. Основи економічного перекладу. Науковий вісник Міжнародного гуманітарного університету. Серія: Філологія. 2014. № 10, том 2. C. $135-137$.
2. Манків Н. Г. Макроекономіка: пер. $з$ англ.; наук. ред. пер. С. Панчишина. Київ : Основи, 2000. 588 с.

3. Мартиненко О. Є. Експериментальна перевірка ефективності методики дистанційного навчання майбутніх перекладачів аудіювання англійською мовою. Вісник КНЛУ. Серія Педагогіка та психологія. 2017. Випуск 26. С. 123-135.

4. Черноватий Л. М. Методика викладання перекладу як спеціальності. Вінниця : Нова Книга, 2013.376 с.

5. Черноватий Л. М. Проблема оцінювання письмових робіт майбутніх перекладачів. Вісник Харківського начіонального університету імені В. Н. Каразіна. Серія: Романо-германська філологія. Методика викладання іноземних мов. 2009. Вип. 848. C. $257-262$.

6. Яслинська К. М. Деякі особливості перекладу фінансово-економічних текстів. Збірник наукових праць Херсонського державного університету. Педагогічні науки. 2017. Вип. 75(3). С. 191-193.

7. González R. C. L. Obstacles in Economic Translation: common, frequent mistakes made by undergraduates. Procedia - Social and Behavioral Sciences. 2015. Vol. 173. P. 331-336.

8. Karnedi P. A cognitive approach to metaphor translation: A case study of translating an economics textbooks from English into Indonesian. Lintas Bahasa Translingua. 2011. Vol. 15 (1). P. 2-31.

9. Karnedi P. Translating economic texts: A case study of epistemicide. TEFLIN Journal. 2015. 26 (1). P. 59-78.

10. Liu N. X. Same perspective, different effect: framing the economy through financial news translation. Perspectives. Studies in Translation Theory and Practice. 2017. Vol. 25 (3). P. 452-463.

11. Mankiw N. G. Macroeconomics. New York : Worth Publishers, 2003. 548 p.

\section{REFERENCES}

1. Kobzar, O. I. (2014). Osnovy ekonomichnoho perekladu [Basics of Economic Translation]. International Humanitarian University Herald. Philology. Vol. 10 (2), pp. 135-137. [in Ukrainian].

2. Mankiw, N. G. (2000). Makroekonomika [Macroeconomics]. (Ed.).S. Panchyshyna. Kyiv, 588 p. [in Ukrainian].

3. Martynenko, O. E. (2017). Eksperymentalna perevirka efektyvnosti metodyky dystantsiinoho navchannia maibutnikh perekladachiv audiiuvannia anhliiskoiu movoiu [Experimental testing of the effectiveness of distance learning methodology of teaching listening comprehension in English to prospective interpreters]. Visnyk KNLU. Series "Pedagogy and Psychology". Vol. 26, pp. 123-135. [in Ukrainian].

4. Chernovatyy, L. M. (2013). Metodyka vykladannya perekladu [Methods of teaching translation]. Vinnytsya, 376 p. [in Ukrainian].

5. Chernovatyi, L. M. (2009). Problema otsiniuvannia pysmovykh robit maibutnikh perekladachiv [The problem of assessing translations produced by future translators]. The Journal of V.N. Karazin Kharkiv National University. Series: Foreign Philology. Methods of Foreign Language Teaching. Vol. 848, pp. 257-262. [in Ukrainian]. 


\section{ОСОБЛИВОСТІ СТАТЕВОГО ВИХОВАННЯ МОЛОДІ В ЗАКЛАДАХ ОСВІТИ КРАЇН-ЗАСНОВНИКІВ ЄВРОПЕЙСЬКОГО МАКРОРЕГІОНУ}

6. Yaslynska, K. M. (2017). Deyaki osoblyvosti perekladu finansovo-ekonomichnykh tekstiv [Some Features of the Translation of Financial and Economic Texts]. Collection of Research Papers "Pedagogical Sciences" of Kherson State University. Vol. 75 (3), pp. 191193. [in Ukrainian].

7. González, R. C. L. (2015). Obstacles in Economic Translation: common, frequent mistakes made by undergraduates. Procedia - Social and Behavioral Sciences. Vol. 173, pp. 331-336. [in English].

8. Karnedi, P. (2011). A cognitive approach to metaphor translation: A case study of translating an economics textbooks from English into Indonesian. Lintas Bahasa Translingua. Vol. 15 (1), pp. 2-31. [in English].

9. Karnedi, P. (2015). Translating economic texts:Acase study of epistemicide. TEFLINJournal.26 (1), pp. 59-78. [inEnglish].

10. Liu, N. X. (2017). Same perspective, different effect: framing the economy through financial news translation. Perspectives. Studies in Translation Theory and Practice. Vol. 25 (3), pp. 452-463. [in English].

11. Mankiw, N. G. (2003). Macroeconomics. New York : Worth Publishers, 2003. 548 p. [in English].

Стаття надійшла до редакції 14.09.2020

УДК 37.03 (4)

DOI:

Оксана Бялик, доктор педагогічних наук, дочент, професор кафедри педагогіки та освітнього менеджменту Уманського державного педагогічного університету імені Павла Тичини

\section{ОСОБЛИВОСТІ СТАТЕВОГО ВИХОВАННЯ МОЛОДІ В ЗАКЛАДАХ ОСВІТИ КРАЇН-ЗАСНОВНИКІВ ЄВРОПЕЙСЬКОГО МАКРОРЕГІОНУ}

У статті зроблена спроба з'ясувати особливості здійснення статевого виховання у різних краӥнах європейського макрорегіону, взявши за основу краӥни-засновники та зробивши акиент на найбільш характерних ознаках ичих країн в означеному аспекті. Зокрема, увага автора зосереджена на Бельгії, Італії, Люксембургу, Нідерландів, Німеччини та Франції у сфері статевого виховання учнів, які започаткували основи формування сучасної шкільної сексуальної освіти на теренах Свропи, надаючи особливу увагу формуванню політики статі, розробленню законодавчої бази з боку інституцій Свросоюзу та Ради Свропи в галузі шкільної освіти.

Ключові слова: виховання; статеве виховання; заклади освіти; учнівська молодь; краӥни-засновники Європейського Союзу; Бельгія; Італія; Люксембург; Нідерланди; Німеччина; Франція.

Jim. 4.

Oksana Byalyk, Doctor of Sciences (Pedagogy), Assosiate Professor of the Pedagogy and Management in Education Department, Uman Pavlo Tychyna State Pedagogical University

\section{PECULIARITIES OF SEXUALEDUCATION OF YOUNG PEOPLE IN EDUCATIONAL INSTITUTIONS OF COUNTRIES-THE FOUNDERS OF THE EUROPEAN MACROREGION}

The article attempts to clarify the peculiarities of sex education in different countries of the European macroregion, based on countries-the founders and emphasize the most characteristic features of these countries in this aspect. In particular, the author focuses on Belgium, Italy, Luxembourg, the Netherlands, Germany and France in the field of sex education of students who have laid the foundations of modern school sex education in Europe, paying special attention to gender policy, EU legal framework and Council of Europe in the field of school education. In Belgium, for example, society has a liberal attitude towards sex and sex education, moreover, sex education is a compulsory practice that offers schools considerable autonomy in the development of curricula, including sex education. Italy is strongly influenced by the Catholic Church, so sex education is controversial in schools, and sex education programs are implemented as part of traditional classroom instruction, focusing mainly on the biological aspects of gender and behavior, adhering to the formation of traditional views on gender issues. based on the principles of morality. Luxembourg has open views on the issue of youth sexuality, the Netherlands shows one of the lowest levels of teenage pregnancy in the world, and the Dutch approach is often seen as a model for other countries. Attitudes toward sex education in Germany are characterized as liberal, accepted and recognized by federal law. This is due to the declining birth rate, which currently requires a rethinking of the position of politicians and the church on sex education and sex education of young people, while continuing to recognize the right of every citizen of the state to start a family. Sex education in France has a holistic approach and plays an important role in the sexual and emotional development of young people, helping them to resist the influence of the media and social 